\title{
Re-examination of the Pt Particle Size Effect on the Oxygen Reduction Reaction for Ultrathin Uniform Pt/C Catalyst Layers without Influence from Nafion
}

\author{
Kazuma Shinozaki ${ }^{\text {a b, c, * }}$, Yu Morimoto ${ }^{c}$, Bryan S. Pivovar $^{\mathrm{a}}$ and Shyam S. Kocha ${ }^{\mathrm{a}}$ \\ ${ }^{a}$ National Renewable Energy Laboratory, Electrochemical Characterization Labs, Golden, CO \\ 80401, USA \\ ${ }^{b}$ Colorado School of Mines - Department of Chemistry, Golden, CO 80401, USA \\ ${ }^{c}$ Toyota Central R\&D Labs., Inc., Aichi, 480-1192 Japan \\ *Corresponding author email: Shinozaki@ mosk.tytlabs.co.jp
}


The platinum 'particle size effect' on the oxygen reduction reaction (ORR) has been re-evaluated using commercial Pt/C catalysts (2-10 nm Pt particle) and polycrystalline $\mathrm{Pt}$ (poly-Pt) in $0.1 \mathrm{M} \mathrm{HClO}_{4}$ with a rotating disk electrode method. Nafion-free catalyst layers were employed to obtain specific activities (SA) that were not perturbed (suppressed) by sulfonate anion adsorption/blocking. By using ultrathin uniform catalyst layers, $\mathrm{O}_{2}$ diffusion limitation was minimized as confirmed from the high SAs of our supported catalysts that were comparable to unsupported sputtered Pt having controlled sizes. The specific activity (SA) steeply increased for the particle sizes in the range $\sim 2-10 \mathrm{~nm}\left(0.8-1.8 \mathrm{~mA} / \mathrm{cm}^{2}{ }_{\mathrm{Pt}}\right.$ at $0.9 \mathrm{~V}$ vs. RHE) and plateaued over $\sim 10 \mathrm{~nm}$ to 2.7 $\mathrm{mA} / \mathrm{cm}_{\mathrm{Pt}}^{2}$ for bulk poly-Pt. On the basis of the activity trend for the range of particle sizes studied, it appears that the effect of carbon support on activity is negligible. The experimental results and the concomitant profile of SA vs. particle size was found to be in an agreement to a truncated octahedral particle model that assumes active terrace sites.

Keywords

Oxygen reduction reaction; Platinum; Particle size effect; Rotating disk electrode method; Nafion-free activity 


\section{Introduction}

Although the platinum loading has been significantly reduced for automotive fuel cells over the last couple of decades, further reduction is necessary from current values of $20-40 \mathrm{~g} \cdot \mathrm{vehicle}^{-1}$ to $5-10 \mathrm{~g} \cdot \mathrm{vehicle}^{-1}$ for successful commercialization [1-3]. A fundamental understanding of the impact of Pt particle size, nature of support, alloying, and heat treatment on the ORR activity and durability is essential to achieve the cost targets. In this work, we primarily address the particle size effect on the ORR activity of cathode catalysts.

The so-called 'particle size effect' (SA vs. Pt particle diameter based on XRD, TEM, CO adsorption, electrochemical area estimated from underpotentially deposited hydrogen ( $\left.\mathrm{H}_{\mathrm{UPD}}\right)$ or $\mathrm{CO}$ stripping) for the ORR on Pt-based catalysts has been debated since 1960's [4-40]. Early works were related to the particle size effect on Teflon-bonded electrodes in phosphoric and sulfuric acid electrolytes (strongly adsorbing anion species) in an attempt to raise phosphoric acid fuel cell (PAFC) performance [4-16]. Some of these studies concluded that there was no specific activity (SA) dependence on Pt particle size; these reports may have suffered from errors caused by extrapolation over several orders of magnitude to obtain the exchange current density

$\left(j_{0}\right)$ [4-7]. A number of subsequent studies have reported an increase in SA with an 
increase in particle size $[6,9,11,12,16]$. Bregoli et al. [9] first reported a clear SA dependence on the particle size between $\sim 3.5 \mathrm{~nm}$ and $30 \mathrm{~nm}$ on the basis of SA at $0.9 \mathrm{~V}$ vs. RHE rather than $j_{0}$. Other groups expanded the range of particle size $(\sim 1 \mathrm{~nm}$ to 50 $\mathrm{nm}$ ) and reported a peak in mass activity (MA) at 3-5 $\mathrm{nm}[11,12]$. Kinoshita [14] rationalized the SA and MA dependence on the particle size, in the range $\sim 1-12 \mathrm{~nm}$, using a truncated octahedral particle model assuming (100) surfaces to be active sites. Markovic et al. [20] demonstrated the activity in dilute sulfuric acid depends on crystallite orientation in the following order: $(111)<(100)<(110)$; this observation agrees with the model reported by Kinoshita [14]. Kabbabi et al. [17] examined the SA and MA in the entire particle size range from $1.8 \mathrm{~nm}$ to bulk polycrystalline $\mathrm{Pt}$ (poly-Pt) for Nafion-coated catalysts in dilute sulfuric acid solution using the rotating disk electrode (RDE) method. They found a similar trend with a steep slope for SA and MA vs. particle size in the range less than $\sim 6 \mathrm{~nm}$; they qualitatively correlated the trend $(2-4.5 \mathrm{~nm})$ to the amount of oxygenated species. Additionally they observed that the slope for the particle size effect was shallower from $\sim 6 \mathrm{~nm}$ to bulk Pt. In contrast, Sarapuu et al. [41] reported no clear particle size dependence of the SA from $\sim 2 \mathrm{~nm}$ to bulk Pt in dilute sulfuric acid solution using Pt thin film fabricated on GCs by electron beam deposition. Nesselberger et al. [31] also observed no clear particle size 
dependence in the range from $\sim 1 \mathrm{~nm}$ to $\sim 5 \mathrm{~nm}$ but a total of $\mathrm{x} 4$ increase from $1-5 \mathrm{~nm}$ particles to bulk Pt, and reported linear MA increase with increasing Pt particle size.

Since the 1990's, researchers have attempted to investigate the particle size effect in dilute perchloric acid (weakly-adsorbing anion species) to simulate Nafion membrane/ionomer employed in proton exchange membrane fuel cell using RDE methods [19-22, 25-37, 39, 40, 42-45]. Although a few reports have concluded an absence of the particle size dependence on the ORR activity [27, 28], the vast majority have reported varying degrees of the effect [19-22, 25, 26, 29-35, 37, 39, 45]. Fabbri et al. [45] recently summarized the particle size dependence reported in 6 articles and compared them to their results; the SA vs. particle size was essentially identical in all the reports when plotted with SA normalized to values at $\sim 10 \mathrm{~nm}$ in each study. The SA dependence was observed to be shallow in the range less than $\sim 10 \mathrm{~nm}$ and steep in the range less than $\sim 10 \mathrm{~nm}$ to bulk poly-Pt. Several research groups have attempted to correlate the particle size effect trend described in Fabbri et al. [45] to the following properties: i) oxide coverage—smaller particles are more oxophilic [19], ii) geometric effect - fraction of terrace/step sites that have different sensitivity to anion adsorption from electrolyte and oxide species [31, 42], iii) surface electronic effects - electrochemical potential of total zero charge (pztc) [25], and, iv) electronic 
effects - binding energy of core (4f) electrons [19], d-band vacancy/position of d-band center $[22,32,37]$. These attempts have succeeded in qualitatively correlating the SA to some of the listed properties in limited ranges; however, none of analyses using practical Pt catalysts provide a reasonable explanation for the SA dependence over the entire particle size range ( $1 \mathrm{~nm}$ particle to bulk). This discrepancy may stem from inaccurate (low) ORR activity determination especially for nanoparticle catalysts as discussed extensively in our previous studies [46-48]. Several factors have been identified that affect the measured ORR activity and consequently the observed particle size effect in $0.1 \mathrm{M} \mathrm{HClO}_{4}$ using RDE methods: i) anion adsorption/blocking by Nafion ionomer-typically, incorporated in $\mathrm{Pt} / \mathrm{C}$ catalyst layers but not for poly-Pt (impact of Nafion may also depend on particle size) [46, 49-56], ii) catalyst layer thickness and uniformity $-\mathrm{O}_{2}$ diffusion within the catalyst layer [33, 35, 45, 46, 57-63], iii) ORR activity measurement protocols [29, 47, 64, 65], iv) $i R$ and background current corrections [21, 31, 47, 66-68], and, v) impurity levels in the electrochemical system $[47,49,59,64,69-76]$.

Nesselberger et al. [31] used Nafion-free catalysts and applied $i R$ and background current corrections in an attempt to obtain a more reliable measure of the particle size effect. However, although their measured activities were higher, the trend essentially 
followed the literature comparison conducted in Fabbri et al. [45]. In order to take into account $\mathrm{O}_{2}$ diffusion limitation within catalyst layer as well, Perez-Alonso et al. [34] employed model Pt nanoparticle ultrathin catalyst layers directly formed on GC substrates (Pt/GC) using an advanced sputtering technique. They reported i) steep SA increase from $2 \mathrm{~nm}$ to $11 \mathrm{~nm}$ particle, ii) similar SA for $11 \mathrm{~nm}$ particle and poly-Pt, and, iii) MA peak at $3 \mathrm{~nm}$. This trend is in sharp contrast to all the literature studies reported using practical Pt catalysts in $0.1 \mathrm{M} \mathrm{HClO}_{4}$ using RDE methods. Their data closely agrees with a theoretical model that assumes truncated octahedral particles with dissolved edges and corners and terrace sites that function as active sites [42]. Since the model experiments using ultrathin catalyst layers, in principle, provide more reliable activity values than the literature experiments using practical Pt catalysts (supported $\mathrm{Pt} / \mathrm{C}$, Pt black), the agreement of the model experiment results with the theoretical model has tremendous significance. However, it is possible that the sputtered highly uniform Pt particles on GC may simulate an ideal nanoparticle catalyst system that may not provide the Pt particle size effect on practical Pt catalyst systems such as $\mathrm{Pt} / \mathrm{C}$ and Pt black.

In this work, we report the ORR activity dependence on Pt particle size for practical $\mathrm{Pt} / \mathrm{C}$ catalysts using highly refined thin-film RDE (TF-RDE) methods. In order to obtain 
the intrinsic ORR activity of Pt surfaces, we employed well-dispersed, Nafion-free ultrathin uniform catalyst layers with ORR activity measured using well-defined protocols determined in our previous study [46].

\section{Experimental}

\subsection{Catalysts, chemicals and reactant gases.}

$\mathrm{Pt} / \mathrm{C}$ catalysts employed in this study were manufactured by Tanaka Kikinzoku Kyogyo (TKK, Japan), Johnson Matthey (JM, UK) and Umicore (Germany), and the detailed specifications along with the nomenclature for the catalysts are listed in Table 1. Surface area obtained from BET method and CO chemisorption and crystallite size from XRD were provided by the manufacturer. Pt/C catalyst with $10 \mathrm{~nm}$ Pt particle (average) was obtained by heat treating Umicore 48 weight $\%$ (wt $\%$ ) $\mathrm{Pt} / \mathrm{C}$ catalyst at $500{ }^{\circ} \mathrm{C}$ under $\mathrm{H}_{2}$ atmosphere for 2 hours. Bulk poly-Pt $\left(\phi=5 \mathrm{~mm}, 0.196 \mathrm{~cm}^{2}\right.$, embedded in a PTFE cylinder, Pine Instruments) were employed in RDE measurements. Deionized (DI) water $(>18.2 \mathrm{M} \Omega \cdot \mathrm{cm}$, TOC $<5 \mathrm{ppb})$ from a Milli Q system (Millipore) was used for acid dilutions and glassware cleaning. The following chemicals were used in electrolyte preparation and ink formulation: isopropanol (IPA, CHROMASOLV ${ }^{\circledR}$ Plus, for HPLC, 99.9\%, Sigma-Aldrich), Nafion solution (DE520, EW1000, $5 \mathrm{wt} \%, 0.924 \mathrm{~g} \cdot \mathrm{cm}^{-3}$, 
Sigma-Aldrich), $0.05 \mu \mathrm{m}$ alumina dispersion (Buehler Inc.), concentrated (conc.) sulfuric acid (Certified ACS Plus, Fisher Scientific), Nochromix ${ }^{\circledR}$ (Godax Laboratories, Inc.), and 70\% perchloric acid Veritas ${ }^{\circledR}$ Doubly Distilled (GFS chemicals). $70 \% \mathrm{HClO}_{4}$ were poured directly from the original acid container into clean perfluoroalkoxy alkane (PFA) or fluorinated ethylene propylene (FEP) bottles placed on a scale, and the $\mathrm{HClO}_{4}$ was poured into DI water in another PFA or FEP bottle to prepare $0.1 \mathrm{M} \mathrm{HClO}_{4}$ electrolyte. All electrochemical measurements were carried out in $0.1 \mathrm{M} \mathrm{HClO}_{4}$. Gases used in this study were all classified as ultrapure grade $\left(\mathrm{N}_{2}, 99.9999 \%, \mathrm{H}_{2}, 99.999 \%\right.$, $\mathrm{O}_{2}, 99.9999 \%, \mathrm{CO} 99.998 \%$ Matheson Gas).

Table 1. Electrocatalyst specification.

\begin{tabular}{|c|c|c|c|c|c|c|}
\hline Supplier & $\begin{array}{c}\mathrm{Pt} \\
\text { content } \\
\text { (wt\%) }\end{array}$ & Carbon & $\begin{array}{l}\text { Nomenclature } \\
\text { for this work }\end{array}$ & $\begin{array}{c}\text { Supplier } \\
\text { nomenclature }\end{array}$ & $\begin{array}{l}\text { Surface } \\
\text { Area CO } \\
\left(\mathrm{m}^{2} \cdot \mathrm{g}^{-1}\right)\end{array}$ & $\begin{array}{c}\text { Crystallite } \\
\text { size } \\
\text { XRD (nm) }\end{array}$ \\
\hline TKK & 26.1 & $\begin{array}{c}\text { High Surface Area } \\
\text { Carbon (HSC) }\end{array}$ & $\mathrm{Pt} / \mathrm{HSC}$ & NA & 271 & 1.8 \\
\hline TKK & 46.4 & HSC & $\mathrm{Pt} / \mathrm{HSC}$ & TEC10E50E & 132.6 & 2.6 \\
\hline TKK & 29 & Vulcan & $\mathrm{Pt} / \mathrm{V}$ & TEC10V30E & 157.3 & 2.5 \\
\hline TKK & 46.4 & Vulcan & $\mathrm{Pt} / \mathrm{V}$ & TEC10V50E & 77.6 & 2.5 \\
\hline TKK & 46.2 & Graphitized Vulcan & $\mathrm{Pt} / \mathrm{G}-\mathrm{V}$ & NA & 70.7 & 2.3 \\
\hline JM & 38 & HSC & $\mathrm{Pt} / \mathrm{HSC}$ & NA & 81 & $<2$ \\
\hline Umicore & 19.5 & $\begin{array}{l}\text { Low Surface Area } \\
\text { Carbon (LSC) }\end{array}$ & Pt/LSC & Elyst Pt20 0380 & NA & $3.0-3.5$ \\
\hline Umicore & 48 & LSC & $\mathrm{Pt} / \mathrm{LSC}$ & Elyst Pt50 0380 & NA & $3.6-4.2$ \\
\hline
\end{tabular}




\subsection{Instrumentation.}

A microbalance (UMX2, Mettler Toredo), bath sonicator (FS30H, Fisher Scientific, output: $42 \mathrm{kHz}, 100 \mathrm{~W}$ ) and horn sonicator (S-4000, QsONICA, LLC., output: $20 \mathrm{kHz}$, $600 \mathrm{~W}$ max) were employed in the preparation of catalyst inks. Autolab PGSTAT302N potentiostat operated with NOVA software from Metrohm was used to obtain cyclic voltammograms (CVs), ORR current-potential (I-E) polarization curves, and to conduct $i R$ correction dynamically during the electrochemical measurements and electrochemical impedance spectroscopy (EIS). RDE rotators, PTFE rotator shafts and GC tips ( $\phi=5 \mathrm{~mm}, 0.196 \mathrm{~cm}^{2}$, embedded in a PTFE cylinder) were obtained from Pine Instruments. An optical microscope (AM4815ZT Dino-Lite Edge, Dino-Lite Digital Microscope) was routinely used to facilitate inspection of catalyst layers on glassy carbon (GC) substrates. A JEOL JSM-7000F Field Emission Microscope was employed to obtain SEM images.

\subsection{Electrochemical cell setup.}

The electrochemical cell design $\left(130 \mathrm{~cm}^{3}\right.$; counter electrode: Pt gauze; reference electrode: RHE; working electrode: poly-Pt or GC with catalyst layer) as well as 
detailed cleaning procedure are described in our previous work [47]. The electrochemical cell was meticulously cleaned as described in detail in our previous work [47]. The GC and poly-Pt RDE tips were polished using $0.05 \mu \mathrm{m}$ alumina slurry before each experiment as described in detail in our previous work [46, 47].

\subsection{Standardized electrochemical measurement protocols.}

Protocols for conditioning, $\mathrm{CVs}$ for electrochemical area (ECA) estimation and ORR I-E curve measurements established on the basis of our comprehensive experimental studies have been meticulously adhered to in this manuscript and we briefly state these measurement protocols [46-48]. For conditioning, potential cycling was conducted in the range $0.025-1.2 \mathrm{~V}$ at $500 \mathrm{mV} \cdot \mathrm{s}^{-1}$ for $50-100$ cycles. $\mathrm{H}_{\mathrm{UPD}}$ (adsorption) charge was obtained from the third cycle of $\mathrm{CV}$ measured in $0.025-1.0 \mathrm{~V}$ at $20 \mathrm{mV} \cdot \mathrm{s}^{-1}$ under $\mathrm{N}_{2}$ atmosphere and ECA was estimated using $210 \mu \mathrm{C} \cdot \mathrm{cm}^{-2}$ Pt [77-80]. We note that HUPD charge estimated in this method resulted in one half of $\mathrm{CO}$ stripping charge for $\mathrm{Pt} / \mathrm{C}$ catalysts [47]. ORR $I-E$ curve was measured from -0.01 to $1.0 \mathrm{~V}$ at $20 \mathrm{mV} \cdot \mathrm{s}^{-1}$ and 1600 rpm under $\mathrm{O}_{2}$ atmosphere, and correction for solution resistance $\left(R_{\text {soln }}\right.$, typically $\sim 21$ ohm) obtained by EIS was applied dynamically during the measurement. Background (b.g.) currents were measured under $\mathrm{N}_{2}$ atmosphere and used for correction for all ORR 
I-E curves. All measurements were conducted at $23 \pm 2^{\circ} \mathrm{C}$. ORR kinetic currents at 82 $\mathrm{kPa}(\sim 1800 \mathrm{~m})$ have been corrected to $100 \mathrm{kPa} \mathrm{O}_{2}$ using reaction order $(\mathrm{m}=1)$ [81-83] and Koutecký-Levich equation was applied to correct for $\mathrm{O}_{2}$ diffusion in electrolyte solution to obtain the SA $\left(\mu \mathrm{A} \cdot \mathrm{cm}^{-2}\right)$ and $\mathrm{MA}\left(\mathrm{mA} \cdot \mathrm{mg}^{-1}{ }_{\mathrm{Pt}}\right)$. The SA and MA are reported at $0.9 \mathrm{~V}$ vs. RHE in this manuscript.

\subsection{Catalyst layer fabrication.}

For TKK Pt/HSC (TEC10E50E), Pt/V and Pt/G-V catalysts, catalyst inks were prepared by mixing Pt/C catalyst powders (46 wt\% Pt/C catalyst: $3.8 \mathrm{mg}, 29 \mathrm{wt} \% \mathrm{Pt} / \mathrm{V}$ : $4.1 \mathrm{mg}$ ) with $7.6 \mathrm{~cm}^{3}$ DI water and $2.4 \mathrm{~cm}^{3}$ IPA, and sonicating in the ice-water bath sonicator $(10 \mathrm{~min})$ followed by sonication using the horn sonicator $(6 \mathrm{~W}, 30 \mathrm{~s})$ with sample vial placed in an ice-water bath. A $5 \mathrm{~mm}^{3}$ aliquot of the catalyst ink (3-4.5 $\mu \mathrm{g}_{\mathrm{Pt}} \cdot \mathrm{cm}^{-2}$ ) was pipetted onto the polished GC tip placed on a custom-built stainless steel holder and positioned in a beaker $\left(400 \mathrm{~cm}^{3}\right)$ filled with $5 \mathrm{~cm}^{3}$ of IPA. The beaker was sealed with a polymer film that was perforated. The beaker with the electrodes and IPA were placed in an oven heated to $40^{\circ} \mathrm{C}$ to gradually ( $\sim 3$ hours) dry the inks under IPA vapor $(\sim 13 \mathrm{kPa})$ and form the catalyst layer [46, 58]. 
For other catalysts (TKK Pt/C except for TEC10E50E, JM Pt/HSC and Umicore Pt/LSC), a high-quality thin layer was not possible without the addition of an extremely small amount of Nafion: catalyst inks were prepared by mixing $\mathrm{Pt} / \mathrm{C}$ catalyst powder (26.1 wt\% Pt/HSC: $2.3 \mathrm{mg}, 38 \mathrm{wt} \% \mathrm{Pt} / \mathrm{HSC}: 2.4 \mathrm{mg}, 19.5 \mathrm{wt} \% \mathrm{Pt} / \mathrm{LSC}: 4.5$ or $9.1 \mathrm{mg}$, $48 \mathrm{wt} \% \mathrm{Pt} / \mathrm{LSC}: 3.7 \mathrm{mg}$ ) with $7.6 \mathrm{~cm}^{3}$ DI water, $2.4 \mathrm{~cm}^{3}$ IPA and $0.5 \mathrm{wt} \%$ Nafion IPA solution (diluted from $5 \mathrm{wt} \%$ Nafion) with ionomer to carbon weight ratio: $\mathrm{I} / \mathrm{C}=0.008$ for $48 \mathrm{wt} \% \mathrm{Pt} / \mathrm{LSC}\left(0.5 \mathrm{wt} \%\right.$ Nafion: $\left.4 \mathrm{~mm}^{3}\right), 0.02-0.04$ for $26.1 \mathrm{wt} \% \mathrm{Pt} / \mathrm{HSC}$ (14 $\left.\mathrm{mm}^{3}\right), 38 \mathrm{wt} \% \mathrm{Pt} / \mathrm{HSC}\left(13 \mathrm{~mm}^{3}\right), 19.5 \mathrm{wt} \% \mathrm{Pt} / \mathrm{LSC}\left(29 \mathrm{~mm}^{3}\right)$, and sonicating with the same procedure as stated above for other $\mathrm{Pt} / \mathrm{C}$ catalysts. A $10 \mathrm{~mm}^{3}$ aliquot of the catalyst ink (3-9 $\mu \mathrm{g}_{\mathrm{Pt}} \cdot \mathrm{cm}^{-2}$ ) was pipetted onto the polished GC tip on an inverted rotator shaft at $100 \mathrm{rpm}$. The ink was subsequently dried under ambient conditions by increasing and maintaining the rotator speed at $700 \mathrm{rpm}$ for a period of $15 \min [46,59]$. For TKK TEC10E50E, both the types of inks were prepared with and without Nafion to examine the influence of Nafion addition. This method provides as thin and uniform catalyst layers for both the types of catalyst inks as shown in Fig. 1. Figure 2 shows that the measured activities are virtually equal with and without the small amount of Nafion addition. We also note that although truly Nafion-free activity cannot be obtained for catalysts that required the addition of slight amount of Nafion to fabricate thin and 
uniform catalyst layers, the impact of the Nafion addition is likely negligible for the I/C range used in this study based on the observation that the activity is invariable for 19.5 wt $\% \mathrm{Pt} / \mathrm{LSC}$ catalyst layers with $\mathrm{I} / \mathrm{C}$ range between 0.02 and 0.04 . Therefore, we treat all the activity values obtained using these two methods as Nafion-free activity values.

\section{Figure 1}

\section{Figure 2}

\section{Results and Discussion}

CVs for poly-Pt, $48 \mathrm{wt} \% \mathrm{Pt} / \mathrm{LSC}$ and $26.1 \mathrm{wt} \% \mathrm{Pt} / \mathrm{HSC}$ catalysts in $0.1 \mathrm{M} \mathrm{HClO}_{4}$ are depicted in Fig. 3a to show the effect of ECA. In order to compare CV characteristics of catalysts with different ECAs, current was normalized with ECA after subtraction of double layer charging current $\left(I_{\mathrm{dl}}\right)$. Peak potentials of Pt surface oxidation and oxide reduction are more positive for catalyst with lower ECAs as reported in literature [19]. ORR I-E curves for these catalysts in $0.1 \mathrm{M} \mathrm{HClO}_{4}$ are also plotted in Fig. $3 b$ to demonstrate reliability of the ORR activity measurement in this study. Agreement of limiting current for the Pt/C catalysts $\left(5.5-5.9 \mathrm{~mA} \cdot \mathrm{cm}^{-2}\right)$ with the theoretical value at $1600 \mathrm{rpm}\left(5.99 \mathrm{~mA} \cdot \mathrm{cm}^{-2}\right)$, calculated using kinematic viscosity 
$\left(1.009 \times 10^{-2} \mathrm{~cm}^{2} \cdot \mathrm{s}^{-1}\right)$, solubility $\left(1.26 \mathrm{~mol} \cdot \mathrm{dm}^{-3}\right)$ and diffusivity $\left(1.90 \times 10^{-5} \mathrm{~cm}^{2} \cdot \mathrm{s}^{-1}\right)$

$[84,85]$, indicates that the catalysts cover almost the entire GC area [46]. Also, i) similar slope on $I-E$ curves for the $\mathrm{Pt} / \mathrm{C}$ catalysts to that for poly-Pt at $\sim 0.85 \mathrm{~V}$ and above, and ii) as sharp transition from mixed kinetic/diffusion regime to $\mathrm{O}_{2}$ diffusion limiting regime on the curves for the $\mathrm{Pt} / \mathrm{C}$ catalysts as that for poly-Pt, suggest that negligible mass transport limitation within Pt/C catalyst layers.

Figure 3

SA values in $0.1 \mathrm{M} \mathrm{HClO}_{4}$ obtained for Pt particle size in the range from $\sim 2 \mathrm{~nm}$ to bulk poly-Pt (4 to 44 electrodes per catalyst, 2 inks per catalyst) along with literature values are depicted in Fig. $4[26,31,34,86]$ and ECA, average particle size and SA can be found in Table 2. The obtained ECA does not agree well with that estimated from $\mathrm{CO}$ chemisorption measurements. The deviation may stem from difference in preconditioning processes and assumption of CO binding mode for ECA estimation [87]. Average particle size was calculated from ECA assuming mono-dispersed sphere having the entire area electrochemically active $[26,31,86]$. The estimated average particle size from $\mathrm{H}_{\mathrm{UPD}}$ charge tends to be larger compared to the crystallite size 
estimated from XRD pattern (Table 1). This could be due to the conditioning process conducted in electrochemical experiments to measure the ORR activity. Since the ORR activity is measured after the conditioning process, we employ average particle size estimated from $\mathrm{H}_{\mathrm{UPD}}$ to discuss particle size effect. SA values obtained in our studies (filled blue circles) is observed in Fig 4 to be significantly higher $\left(0.74-1.8 \mathrm{~mA} \cdot \mathrm{cm}^{-2} \mathrm{Pt}\right.$ ) in the range $(\sim 2-10 \mathrm{~nm})$ than those reported in literature $\left(0.2-0.5 \mathrm{~mA} \cdot \mathrm{cm}^{-2} \mathrm{Pt}\right)$ using practical Pt catalysts [26, 31] but comparable to that of Perez-Alonso et al. [34]. On the basis of findings in our previous studies, the high values are due to i) exclusion of Nafion ionomer that lowers the ORR activity, ii) the use of thin and uniform catalyst layers with negligible $\mathrm{O}_{2}$ diffusion limitation within the catalyst layer, iii) the use of ORR activity measurement protocols with appropriate conditioning and corrections, and iv) minimized impact of impurity in the electrochemical system on the activity. Our understanding can be rationalized when our results are compared to the results reported by Perez-Alonso et al. [34], who used model electrodes in which Pt particles were deposited directly onto GC substrates (denote as sputtered Pt/GC hereafter) by an advanced sputtering technique. Because of the nature of the deposition technique, the catalyst layers obtained in Perez-Alonso et al. [34] are extremely thin, Nafion is not incorporated and ORR activity measurement protocols are similar to the protocols 
applied in this work. Thus, the catalyst layers in the sputtered Pt/GC experiments should result in ORR activities of $\mathrm{Pt}$ with negligible loss due to $\mathrm{O}_{2}$ diffusion limitation. On the basis of these facts, it is reasonable to treat the high SA values in our study as approaching the intrinsic activity of $\mathrm{Pt}$ nanoparticles with minimal impact from $\mathrm{O}_{2}$ diffusion limitation and impurities.

\section{Figure 4}

Table 2. Comparison of ECA, SA and MA for Pt/C catalysts

\begin{tabular}{ccccccc}
\hline catalyst & \# of samples & ECA $\left(\mathbf{m}^{2} \cdot \mathbf{g}^{-1}\right)$ & $\begin{array}{c}\text { Average particle } \\
\text { size }(\mathbf{n m})\end{array}$ & SA $\left(\mathbf{m A} \cdot \mathbf{c m}^{-2}{ }_{\mathrm{Pt}}\right)$ & MA $\left(\mathbf{m A} \cdot \mathbf{m g}^{-1} \mathbf{P t}\right)$ & Reference \\
\hline $26.1 \mathrm{wt} \% \mathrm{Pt} / \mathrm{HSC}$ & 6 & $136 \pm 3$ & 2.1 & $0.74 \pm 0.03$ & $1.01 \pm 0.05$ & This work \\
$46.4 \mathrm{wt} \% \mathrm{Pt} / \mathrm{HSC}$ & 44 & $101 \pm 7$ & 2.8 & $0.89 \pm 0.06$ & $0.90 \pm 0.09$ & {$[46]$} \\
$29 \mathrm{wt} \% \mathrm{Pt} / \mathrm{V}$ & 6 & $93.5 \pm 0.9$ & 3.0 & $1.01 \pm 0.06$ & $0.94 \pm 0.06$ & This work \\
$46.4 \mathrm{wt} \% \mathrm{Pt} / \mathrm{V}$ & 20 & $63 \pm 3$ & 4.4 & $1.12 \pm 0.07$ & $0.71 \pm 0.04$ & {$[46]$} \\
$46.2 \mathrm{wt} \% \mathrm{Pt} / \mathrm{G}-\mathrm{V}$ & 6 & $54 \pm 4$ & 5.2 & $1.17 \pm 0.06$ & $0.63 \pm 0.05$ & This work \\
$38 \mathrm{wt} \% \mathrm{Pt} / \mathrm{HSC}$ & 5 & $120 \pm 3$ & 2.3 & $0.82 \pm 0.02$ & $0.98 \pm 0.04$ & This work \\
$19.5 \mathrm{wt} \% \mathrm{Pt} / \mathrm{LSC}$ & 8 & $66.4 \pm 0.8$ & 4.2 & $1.13 \pm 0.03$ & $0.75 \pm 0.02$ & This work \\
$48 \mathrm{wt} \% \mathrm{Pt} / \mathrm{LSC}$ & 6 & $48.0 \pm 0.3$ & 5.8 & $1.79 \pm 0.05$ & $0.86 \pm 0.02$ & This work \\
$48 \mathrm{wt} \% \mathrm{Pt} / \mathrm{LSC}-\mathrm{HT}{ }^{*}$ & 4 & $28 \pm 1$ & 9.9 & $1.67 \pm 0.09$ & $0.471 \pm 0.009$ & This work \\
\hline
\end{tabular}

*HT: heat-treated 
The impurity level in the cell/electrolyte can be judged from the magnitude of SA of bulk poly-Pt; the SA of poly-Pt ranges $2-3 \mathrm{~mA} \cdot \mathrm{cm}_{\mathrm{Pt}}^{-2}$ in these studies (Fig. 4). By normalizing to the SA for poly-Pt, it may be possible to make a more fair comparison of the trend and be able to make a comparison to the theoretical model. Figure 4 has been re-plotted as Fig. 5 with SA normalized to poly-Pt SA for each data set [26, 31, 34, 42, 86]. Figure 5 includes a curve representing a theoretical model (truncated octahedral particle with dissolved edges and corners) reported by Tritsaris et al. [42]. The SA value corresponding to $\sim 30 \mathrm{~nm}$ evaluated in our group using Nafion-free Pt nanotube thin catalyst layer (blue open circle) has also been added to Fig. 5. In literature studies [26, 31], SA remains low in the range from $\sim 2 \mathrm{~nm}$ to $8 \mathrm{~nm}$ but significantly increases in the range from $\sim 8 \mathrm{~nm}$ to bulk poly-Pt. In our study, in contrast, SA at $\sim 2 \mathrm{~nm}$ is already as high as $\sim 30 \%$ of SA for poly-Pt, and SA steeply increases to $60-70 \%$ of SA for poly-Pt at $\sim 10 \mathrm{~nm}$ followed by attenuated increase and plateau to reach bulk poly-Pt activity. The trend in our study is coincident with most of the sputtered Pt/GC data and is in close agreement to the theoretical model. Figure 6 is a plot of the normalized SA vs. particle size with the second ordinate representing fraction of terrace atoms obtained experimentally for the catalyst of Perez-Alonso et al. [34]. Since our data for practical catalysts falls in the same range as that of Perez-Alonso et al. [34], it follows that 
despite the wider particle size distribution the SA for practical catalysts show good correlation to terrace atom fraction. The samples used in our study include various types of carbon supports as well as bulk poly-Pt; the correlation suggests that there is minimal interaction with the carbon supports that affects the ORR activity. In simple terms, we may conclude that the intrinsic activity of $\mathrm{Pt}$ at $0.9 \mathrm{~V}$ is proportional to the number of terrace sites. We note that the so-called "particle proximity effect" on the ORR activity is not likely to be affecting the SA values on Pt/C catalysts used in this study [88]; calculated average inter-particle distance (AID) or edge to edge distance using an equation reported in literature ranges from $8 \mathrm{~nm}$ to $23 \mathrm{~nm}$ for $\mathrm{Pt} / \mathrm{C}$ catalysts used in our study [89]. Although the calculated AID provides only an indicative average, the AID range for catalysts used in our study are still significantly longer than inter-particle distances that have been reported to increase the ORR activity $(<1.5 \mathrm{~nm})$ in literature study [88].

\section{Figure 5}

\section{Figure 6}


The absolute values of MA obtained in our and literature studies are summarized in Fig. $7[26,31,34,42,86]$ and can also be found in Table 2. The MA obtained in our work is significantly higher than that reported in the literature using practical $\mathrm{Pt}$ catalysts and is in close agreement with that for sputtered Pt/GC measurements and the theoretical model. An MA decrease for particle sizes below $~ 2 \mathrm{~nm}$ was not observed in our studies due to both a lack of available samples/data in that range as well as a finite particle size distribution for practical catalysts.

\section{Figure 7}

\section{Conclusion}

Pt particle size effect on the ORR activity was studied in the range from $2 \mathrm{~nm}$ to bulk poly-Pt using practical $\mathrm{Pt} / \mathrm{C}$ catalysts and poly-Pt in $0.1 \mathrm{M} \mathrm{HClO}_{4}$. By incorporating experimental advancements (Nafion-free ultrathin uniform catalyst layers and standardized protocols): i) extremely high SA and MA for practical catalysts comparable to the sputtered Pt/GC (approaching an ideal system) were obtained, ii) the particle size effect for practical catalysts in our work agreed with the theoretical model 
that assumed truncated octahedral particles with terrace sites to be active, iii) no strong interaction with the carbon supports was observable.

\section{Acknowledgement}

Shyam S. Kocha gratefully acknowledges funding from the U.S. Department of Energy, Fuel Cells Technologies Program under Contract No. DE-AC36-08-GO28308 to the National Renewable Energy Laboratory. Kazuma Shinozaki's stay at NREL and CSM was funded by Toyota Central R\&D Labs., Inc. We would like to acknowledge Umicore for providing their catalysts, and Dr. Katie Hurst in NREL for heat treating a catalyst. 


\section{References}

[1] D. Papageorgopoulos, Fuel Cells Overview, Annual Merit Review Proceedings Fuel Cells, (2014).

[2] S.S. Kocha, Electrochemical Degradation : Electrocatalyst and Support Durability, in: M. Mench, E.C. Kumbur, T.N. Veziroglu (Eds.) Polymer Electrolyte Fuel Cell Degradation, Elsevier Inc., 2012, pp. 89-214.

[3] A. Iiyama, K. Shinohara, S. Iguchi, A. Daimaru, in: W. Vielstich, H.A. Gasteiger, H. Yokokawa (Eds.) Handbook of Fuel Cells: Advances in Electrocatalysis, Materials, Diagnostics and Durability, Wiley, Chichester, UK, 2009, pp. 1090.

[4] H.I. Zeliger, Fuel Cell Performance as a Function of Catalyst Surface Area, Journal of The Electrochemical Society, 114 (1967) 144.

[5] W.M. Vogel, J.T. Lundquist, Reduction of Oxygen on Teflon-Bonded Platinum Electrodes, Journal of The Electrochemical Society, 117 (1970) 1512.

[6] K.F. Blurton, P. Greenberg, H.G. Oswin, D.R. Rutt, The Electrochemical Activity of Dispersed Platinum, Journal of The Electrochemical Society, 119 (1972) 559.

[7] J. Bett, J. Lundquist, E. Washington, P. Stonehart, Platinum crystallite size considerations for electrocatalytic oxygen reduction-I, Electrochimica Acta, 18 (1973) 343.

[8] H.R. Kunz, G.A. Gruver, The Catalytic Activity of Platinum Supported on Carbon for Electrochemical Oxygen Reduction in Phosphoric Acid, Journal of The Electrochemical Society, 122 (1975) 1279.

[9] L.J. Bregoli, The influence of platinum crystallite size on the electrochemical reduction of oxygen in phosphoric acid, Electrochimica Acta, 23 (1978) 489.

[10] P.N. Ross, Structure Sensitivity in Electrocatalytic Properties of Pt, Journal of The Electrochemical Society, 126 (1979) 78.

[11] M. Peuckert, T. Yoneda, R.A. Dalla Betta, M. Boudart, Oxygen Reduction on Small Supported Platinum Particles, Journal of The Electrochemical Society, 133 (1986) 944.

[12] M. Sattler, P. Ross, The surface structure of Pt crystallites supported on carbon black, Ultramicroscopy, 20 (1986) 21.

[13] M. Watanabe, S. Saegusa, P. Stonehart, Electro-catalytic activity on supported platinum crystallites for oxygen reduction in sulphuric acid, Chemistry Letters, (1988) 1487. 
[14] K. Kinoshita, Particle Size Effects for Oxygen Reduction on Highly Dispersed Platinum in Acid Electrolytes, Journal of The Electrochemical Society, 137 (1990) 845. [15] S. Mukerjee, Particle size and structural effects in platinum electrocatalysis, Journal of Applied Electrochemistry, 20 (1990) 537.

[16] N. Giordano, E. Passalacqua, L. Pino, A.S. Arico, V. Antonucci, M. Vivaldi, K. Kinoshita, Analysis of platinum particle size and oxygen reduction in phosphoric acid, Electrochimica Acta, 36 (1991) 1979.

[17] A. Kabbabi, F. Gloaguen, F. Andolfatto, R. Durand, Particle size effect for oxygen reduction and methanol oxidation on $\mathrm{Pt} / \mathrm{C}$ inside a proton exchange membrane, Journal of Electroanalytical Chemistry, 373 (1994) 251.

[18] G. Tamizhmani, J.P. Dodelet, D. Guay, Crystallite Size Effects of Carbon-Supported Platinum on Oxygen Reduction in Liquid Acids, Journal of The Electrochemical Society, 143 (1996) 18.

[19] Y. Takasu, N. Ohashi, X.-G. Zhang, Y. Murakami, H. Minagawa, S. Sato, K. Yahikozawa, Size effects of platinum particles on the electroreduction of oxygen, Electrochimica Acta, 41 (1996) 2595.

[20] N. Markovic, H. Gasteiger, P. Ross, Kinetics of oxygen reduction on Pt (hkl) electrodes: implications for the crystallite size effect with supported Pt electrocatalysts, Journal of The Electrochemical Society, 144 (1997) 1591.

[21] S.L. Gojković, S.K. Zecevic, R.F. Savinell, O[sub 2] Reduction on an Ink-Type Rotating Disk Electrode Using Pt Supported on High-Area Carbons, Journal of The Electrochemical Society, 145 (1998) 3713.

[22] S. Mukerjee, J. McBreen, Effect of particle size on the electrocatalysis by carbon-supported Pt electrocatalysts: an in situ XAS investigation, Journal of Electroanalytical Chemistry, 448 (1998) 163.

[23] J. Perez, E.R. Gonzalez, E.A. Ticianelli, Oxygen electrocatalysis on thin porous coating rotating platinum electrodes, Electrochimica Acta, 44 (1998) 1329.

[24] O. Antoine, Y. Bultel, R. Durand, Oxygen reduction reaction kinetics and mechanism on platinum nanoparticles inside Nafion ${ }^{\circledR}$, Journal of Electroanalytical Chemistry, 499 (2001) 85.

[25] K.J.J. Mayrhofer, B.B. Blizanac, M. Arenz, V.R. Stamenkovic, P.N. Ross, N.M. Markovic, The impact of geometric and surface electronic properties of pt-catalysts on the particle size effect in electrocatalysis., The journal of physical chemistry. B, 109 (2005) 14433. 
[26] H.A. Gasteiger, S.S. Kocha, B. Sompalli, F.T. Wagner, Activity benchmarks and requirements for $\mathrm{Pt}, \mathrm{Pt}$-alloy, and non-Pt oxygen reduction catalysts for PEMFCs, Applied Catalysis B: Environmental, 56 (2005) 9.

[27] H. Yano, E. Higuchi, H. Uchida, M. Watanabe, Temperature dependence of oxygen reduction activity at Nafion-coated bulk Pt and Pt/carbon black catalysts., The journal of physical chemistry. B, 110 (2006) 16544.

[28] H. Yano, J. Inukai, H. Uchida, M. Watanabe, P.K. Babu, T. Kobayashi, J.H.

Chung, E. Oldfield, A. Wieckowski, Particle-size effect of nanoscale platinum catalysts in oxygen reduction reaction: an electrochemical and 195Pt EC-NMR study., Physical chemistry chemical physics : PCCP, 8 (2006) 4932.

[29] K.J.J. Mayrhofer, D. Strmcnik, B.B. Blizanac, V. Stamenkovic, M. Arenz, N.M. Markovic, Measurement of oxygen reduction activities via the rotating disc electrode method: From Pt model surfaces to carbon-supported high surface area catalysts, Electrochimica Acta, 53 (2008) 3181.

[30] H. Ye, J.A. Crooks, R.M. Crooks, Effect of particle size on the kinetics of the electrocatalytic oxygen reduction reaction catalyzed by Pt dendrimer-encapsulated nanoparticles., Langmuir : the ACS journal of surfaces and colloids, 23 (2007) 11901. [31] M. Nesselberger, S. Ashton, J.C. Meier, I. Katsounaros, K.J.J. Mayrhofer, M. Arenz, The particle size effect on the oxygen reduction reaction activity of Pt catalysts: influence of electrolyte and relation to single crystal models., Journal of the American Chemical Society, 133 (2011) 17428.

[32] E. Toyoda, R. Jinnouchi, T. Hatanaka, Y. Morimoto, K. Mitsuhara, A. Visikovskiy, Y. Kido, The d-Band Structure of Pt Nanoclusters Correlated with the Catalytic Activity for an Oxygen Reduction Reaction, The Journal of Physical Chemistry C, 115 (2011) 21236.

[33] O.J. Curnick, B.G. Pollet, P.M. Mendes, Nafion®-stabilised Pt/C electrocatalysts with efficient catalyst layer ionomer distribution for proton exchange membrane fuel cells, RSC Advances, 2 (2012) 8368.

[34] F.J. Perez-Alonso, D.N. McCarthy, A. Nierhoff, P. Hernandez-Fernandez, C. Strebel, I.E.L. Stephens, J.H. Nielsen, I. Chorkendorff, The effect of size on the oxygen electroreduction activity of mass-selected platinum nanoparticles., Angewandte Chemie (International ed. in English), 51 (2012) 4641.

[35] K. Ke, K. Hiroshima, Y. Kamitaka, T. Hatanaka, Y. Morimoto, An accurate evaluation for the activity of nano-sized electrocatalysts by a thin-film rotating disk electrode: Oxygen reduction on Pt/C, Electrochimica Acta, 72 (2012) 120. 
[36] Y. Kawamura, R. Jinnouchi, Theoretical study of particle size effect on oxygen reduction reaction on Pt catalyst, ECS Transactions, 50 (2012) 1321.

[37] W. Sheng, S. Chen, E. Vescovo, Y. Shao-Horn, Size Influence on the Oxygen Reduction Reaction Activity and Instability of Supported Pt Nanoparticles, Journal of The Electrochemical Society, 159 (2012) B96.

[38] C. Wang, N.M. Markovic, V.R. Stamenkovic, Advanced Platinum Alloy Electrocatalysts for the Oxygen Reduction Reaction, ACS Catalysis, 2 (2012) 891. [39] J. Speder, L. Altmann, M. Roefzaad, M. Bäumer, J.J.K. Kirkensgaard, K. Mortensen, M. Arenz, Pt based PEMFC catalysts prepared from colloidal particle suspensions--a toolbox for model studies., Physical chemistry chemical physics : PCCP, 15 (2013) 3602.

[40] D. Li, C. Wang, D.S. Strmcnik, D.V. Tripkovic, X. Sun, Y. Kang, M. Chi, J.D. Snyder, D. van der Vliet, Y. Tsai, V.R. Stamenkovic, S. Sun, N.M. Markovic, Functional links between Pt single crystal morphology and nanoparticles with different size and shape: the oxygen reduction reaction case, Energy Environ. Sci., 7 (2014) 4061 .

[41] A. Sarapuu, A. Kasikov, T. Laaksonen, K. Kontturi, K. Tammeveski, Electrochemical reduction of oxygen on thin-film Pt electrodes in acid solutions, Electrochimica Acta, 53 (2008) 5873-5880.

[42] G.A. Tritsaris, J. Greeley, J. Rossmeisl, J.K. Nørskov, Atomic-Scale Modeling of Particle Size Effects for the Oxygen Reduction Reaction on Pt, Catalysis Letters, 141 (2011) 909.

[43] L. Li, A.H. Larsen, N.A. Romero, V.A. Morozov, C. Glinsvad, F. Abild-Pedersen, J. Greeley, K.W. Jacobsen, J.K. Nørskov, Investigation of Catalytic Finite-Size-Effects of Platinum Metal Clusters, The Journal of Physical Chemistry Letters, 4 (2013) 222. [44] V. Tripković, I. Cerri, T. Bligaard, J. Rossmeisl, The influence of particle shape and size on the activity of platinum nanoparticles for oxygen reduction reaction: A density functional theory study, Catalysis Letters, 144 (2014) 380.

[45] E. Fabbri, S. Taylor, A. Rabis, P. Levecque, O. Conrad, R. Kötz, T.J. Schmidt, The effect of platinum nanoparticle distribution on oxygen electroreduction activity and selectivity, ChemCatChem, 6 (2014) 1410.

[46] K. Shinozaki, J.W. Zack, S. Pylypenko, B.S. Pivovar, S.S. Kocha, Oxygen

Reduction Reaction Measurements on Platinum Electrocatalysts Utilizing Rotating Disk Electrode Technique, Journal of The Electrochemical Society, 162 (2015) F1384. [47] K. Shinozaki, J.W. Zack, R.M. Richards, B.S. Pivovar, S.S. Kocha, Oxygen Reduction Reaction Measurements on Platinum Electrocatalysts Utilizing Rotating Disk 
Electrode Technique: I. Impact of Impurities, Measurement Protocols and Applied Corrections, Journal of The Electrochemical Society, 162 (2015) F1144.

[48] K. Shinozaki, J.W. Zack, S. Pylypenko, R.M. Richards, B.S. Pivovar, S.S. Kocha, Benchmarking the oxygen reduction reaction activity of Pt-based catalysts using standardized rotating disk electrode methods, International Journal of Hydrogen Energy, 40 (2015) 16820.

[49] R. Subbaraman, D. Strmcnik, V. Stamenkovic, N.M. Markovic, Three Phase Interfaces at Electrified Metal-Solid Electrolyte Systems 1. Study of the Pt( hkl )-Nafion Interface, The Journal of Physical Chemistry C, 114 (2010) 8414.

[50] R. Subbaraman, D. Strmcnik, A.P. Paulikas, V.R. Stamenkovic, N.M. Markovic, Oxygen reduction reaction at three-phase interfaces., ChemPhysChem : A European journal of chemical physics and physical chemistry, 11 (2010) 2825.

[51] A.M. Gómez-Marín, A. Berná, J.M. Feliu, Spectroelectrochemical Studies of the $\mathrm{Pt}(111)$ /Nafion Interface Cast Electrode, The Journal of Physical Chemistry C, 114 (2010) 20130.

[52] M. Ahmed, D. Morgan, G.A. Attard, E. Wright, D. Thompsett, J. Sharman, Unprecedented Structural Sensitivity toward Average Terrace Width: Nafion Adsorption at Pt $\{$ hkl $\}$ Electrodes, The Journal of Physical Chemistry C, 115 (2011) 17020.

[53] K. Kodama, A. Shinohara, N. Hasegawa, K. Shinozaki, R. Jinnouchi, T. Suzuki, T. Hatanaka, Y. Morimoto, Catalyst Poisoning Property of Sulfonimide Acid Ionomer on Pt (111) Surface, Journal of the Electrochemical Society, 161 (2014) F649.

[54] D. Chu, D. Tryk, D. Gervasio, E.B. Yeager, Examination of the ionomer/electrode interface using the ferric/ferrous redox couple, Journal of Electroanalytical Chemistry and Interfacial Electrochemistry, 272 (1989) 277.

[55] A. Ohma, K. Fushinobu, K. Okazaki, Influence of Nafion® film on oxygen reduction reaction and hydrogen peroxide formation on Pt electrode for proton exchange membrane fuel cell, Electrochimica Acta, 55 (2010) 8829.

[56] J. Maruyama, M. Inaba, K. Katakura, Z. Ogumi, Z.-i. Takehara, Influence of Nafion ${ }^{\circledR}$ film on the kinetics of anodic hydrogen oxidation, Journal of Electroanalytical Chemistry, 447 (1998) 201.

[57] T.J. Schmidt, H.A. Gasteiger, G.D. Stab, D.M. Kolb, R.J. Behm, Characterization of High-Surface-Area Electrocatalysts Using a Rotating Disk Electrode Configuration, Journal of The Electrochemical Society, 145 (1998) 2354. 
[58] E. Higuchi, H. Uchida, M. Watanabe, Effect of loading level in platinum-dispersed carbon black electrocatalysts on oxygen reduction activity evaluated by rotating disk electrode, Journal of Electroanalytical Chemistry, 583 (2005) 69.

[59] Y. Garsany, O.A. Baturina, K.E. Swider-Lyons, S.S. Kocha, Experimental methods for quantifying the activity of platinum electrocatalysts for the oxygen reduction reaction, Analytical Chemistry, 82 (2010) 6321.

[60] Y. Garsany, I.L. Singer, K.E. Swider-Lyons, Impact of film drying procedures on $\mathrm{RDE}$ characterization of Pt/VC electrocatalysts, Journal of Electroanalytical Chemistry, 662 (2011) 396.

[61] Y. Garsany, J. Ge, J. St-Pierre, R. Rocheleau, K.E. Swider-Lyons, Analytical Procedure for Accurate Comparison of Rotating Disk Electrode Results for the Oxygen Reduction Activity of Pt/C, Journal of the Electrochemical Society, 161 (2014) F628. [62] P. Jovanoviča, A. Pavlišič, M. Bele, S. Hočevar, N. Hodnik, M. Gaberšček, Evaluation of oxygen reduction activity of non-ideal Pt based catalyst thin films, ECS Transactions, 68 (2015) 141.

[63] F. Gloaguen, F. Andolfatto, R. Durand, P. Ozil, Kinetic study of electrochemical reactions at catalyst-recast ionomer interfaces from thin active layer modelling, Journal of Applied Electrochemistry, 24 (1994) 863.

[64] N. Hodnik, C. Baldizzone, S. Cherevko, A. Zeradjanin, K.J.J. Mayrhofer, The Effect of the Voltage Scan Rate on the Determination of the Oxygen Reduction Activity of Pt/C Fuel Cell Catalyst, Electrocatalysis, 6 (2015) 237-241.

[65] I.A. Pasti, N.M. Gavrilov, S.V. Mentus, Potentiodynamic Investigation of Oxygen Reduction Reaction on Polycrystalline Platinum Surface in Acidic Solutions: the Effect of the Polarization Rate on the Kinetic Parameters, International Journal of electrochemical Science, 7 (2012) 11076.

[66] D. van der Vliet, D.S. Strmcnik, C. Wang, V.R. Stamenkovic, N.M. Markovic, M.T.M. Koper, On the importance of correcting for the uncompensated Ohmic resistance in model experiments of the Oxygen Reduction Reaction, Journal of Electroanalytical Chemistry, 647 (2010) 29.

[67] D.R. Lawson, L.D. Whiteley, C.R. Martin, M.N. Szentirmay, J.I. Song, Oxygen Reduction at Nafion Film-Coated Platinum Electrodes: Transport and Kinetics, Journal of The Electrochemical Society, 135 (1988) 2247.

[68] F.A. Uribe, T.E. Springer, G. Shimshon, A Microelectrode Study of Oxygen Reduction at the Platinum/Recast-Nafion Film Interface, Journal of The Electrochemical Society, 1992, pp. 765. 
[69] T.J. Schmidt, U.A. Paulus, H.A. Gasteiger, R.J. Behm, The oxygen reduction reaction on a Pt/carbon fuel cell catalyst in the presence of chloride anions, Journal of Electroanalytical Chemistry, 508 (2001) 41.

[70] W. Pell, A. Zolfaghari, B. Conway, Capacitance of the double-layer at polycrystalline Pt electrodes bearing a surface-oxide film, Journal of Electroanalytical Chemistry, 532 (2002) 13.

[71] G.E. Dima, G.L. Beltramo, M.T.M. Koper, Nitrate reduction on single-crystal platinum electrodes, Electrochimica Acta, 50 (2005) 4318.

[72] K. Nakata, Y. Kayama, K. Shimazu, A. Yamakata, S. Ye, M. Osawa,

Surface-enhanced infrared absorption spectroscopic studies of adsorbed nitrate, nitric oxide, and related compounds 2: Nitrate ion adsorption at a platinum electrode., Langmuir : the ACS journal of surfaces and colloids, 24 (2008) 4358.

[73] E.B. Molodkina, M.R. Ehrenburg, Y.M. Polukarov, A.I. Danilov, J. Souza-Garcia, J.M. Feliu, Electroreduction of nitrate ions on Pt(111) electrodes modified by copper adatoms, Electrochimica Acta, 56 (2010) 154.

[74] G.E. Dima, A.C.A. de Vooys, M.T.M. Koper, Electrocatalytic reduction of nitrate at low concentration on coinage and transition-metal electrodes in acid solutions, Journal of Electroanalytical Chemistry, 554-555 (2003) 15.

[75] M.C.P.M. da Cunha, M. Weber, F.C. Nart, On the adsorption and reduction of NO3- ions at Au and Pt electrodes studied by in situ FTIR spectroscopy, Journal of Electroanalytical Chemistry, 414 (1996) 163.

[76] S. Sugawara, T. Maruyama, Y. Nagahara, S.S. Kocha, K. Shinohara, K. Tsujita, S. Mitsushima, K.-i. Ota, Performance decay of proton-exchange membrane fuel cells under open circuit conditions induced by membrane decomposition, Journal of Power Sources, 187 (2009) 324.

[77] S. Gilman, A STUDY OF THE MECHANISM OF CARBON MONOXIDE ADSORPTION ON PLATINUM BY A NEW ELECTROCHEMICAL PROCEDURE 1, The Journal of Physical Chemistry, 67 (1963) 78.

[78] S. Gilman, Measurement of hydrogen adsorption by the multipulse potentiodynamic (mpp) method, Journal of Electroanalytical Chemistry (1959), 7 (1964) 382.

[79] S.B. Brummer, The Use of Large Anodic Galvanostatic Transients to Evaluate the Maximum Adsorption on Platinum from Formic Acid Solutions, The Journal of Physical Chemistry, 69 (1965) 562. 
[80] T. Biegler, R. Woods, Limiting oxygen coverage on smooth platinum anodes in acid solution, Journal of Electroanalytical Chemistry and Interfacial Electrochemistry, 20 (1969) 73.

[81] A. Damjanovic, V. Brusic, Electrode kinetics of oxygen reduction on oxide-free platinum electrodes, Electrochimica Acta, 12 (1967) 615.

[82] N.M. Marković, R.R. Adžić, B.D. Cahan, E.B. Yeager, Structural effects in electrocatalysis: oxygen reduction on platinum low index single-crystal surfaces in perchloric acid solutions, Journal of Electroanalytical Chemistry, 377 (1994) 249. [83] U.A. Paulus, A. Wokaun, G.G. Scherer, T.J. Schmidt, V. Stamenkovic, N.M. Markovic, P.N. Ross, Oxygen reduction on high surface area Pt-based alloy catalysts in comparison to well defined smooth bulk alloy electrodes, Electrochimica Acta, 47 (2002) 3787.

[84] K.E. Gubbins, R.D. Walker, The Solubility and Diffusivity of Oxygen in Electrolytic Solutions, Journal of The Electrochemical Society, 112 (1965) 469. [85] N.M. Markovic, H.A. Gasteiger, P.N. Ross, Oxygen Reduction on Platinum Low-Index Single-Crystal Surfaces in Sulfuric Acid Solution: Rotating Ring-Pt(hkl) Disk Studies, The Journal of Physical Chemistry, 99 (1995) 3411. [86] A.B. Papandrew, R.W. Atkinson, G.A. Goenaga, S.S. Kocha, J.W. Zack, B.S. Pivovar, T.A. Zawodzinski, Oxygen Reduction Activity of Vapor-Grown Platinum Nanotubes, Journal of the Electrochemical Society, 160 (2013) F848.

[87] K. Shinozaki, H. Yamada, Y. Morimoto, Relative Humidity Dependence of Pt Utilization in Polymer Electrolyte Fuel Cell Electrodes: Effects of Electrode Thickness, Ionomer-to-Carbon Ratio, Ionomer Equivalent Weight, and Carbon Support, Journal of The Electrochemical Society, 158 (2011) B467.

[88] M. Nesselberger, M. Roefzaad, R.F. Hamou, P.U. Biedermann, F.F. Schweinberger, S. Kunz, K. Schloegl, G.K.H. Wiberg, S. Ashton, U. Heiz, K.J.J. Mayrhofer, M. Arenz, The effect of particle proximity on the oxygen reduction rate of size-selected platinum clusters., Nature materials, 12 (2013) 919.

[89] J.C. Meier, C. Galeano, I. Katsounaros, J. Witte, H.J. Bongard, A.A. Topalov, C. Baldizzone, S. Mezzavilla, F. Schuth, K.J. Mayrhofer, Design criteria for stable Pt/C fuel cell catalysts, Beilstein journal of nanotechnology, 5 (2014) 44. 


\section{Figure Captions}

Figure 1. SEM images of TKK $46 \mathrm{wt} \% \mathrm{Pt} / \mathrm{HSC}$ catalyst layers fabricated on GC substrates using (a) the Nafion-free method and (b) the low Nafion content method (I/C 0.02). Catalysts removed as observable as horizontal lines on both catalyst layers to facilitate observation and analysis of catalyst distribution in each local area ( $80 \%$ of the catalysts located in the area of $<0.5 \mu \mathrm{m}$ in thickness for both catalyst layers).

Figure 2. SA at $0.9 \mathrm{~V}$ obtained for TKK $46 \mathrm{wt} \% \mathrm{Pt} / \mathrm{HSC}$ catalyst layers fabricated with the Nafion-free method and the low Nafion content method.

Figure 3. (a) CVs and (b) ORR I-E curves for poly-Pt and $\mathrm{Pt} / \mathrm{C}$ catalyst layers at 20 $\mathrm{mV} \cdot \mathrm{s}^{-1}$ and $23^{\circ} \mathrm{C}$ in $0.1 \mathrm{M} \mathrm{HClO}_{4}$. B.g. current correction applied for the ORR I-E curves.

Figure 4. Particle size dependence of specific activity at $0.9 \mathrm{~V}$ vs. RHE in $0.1 \mathrm{M} \mathrm{HClO}_{4}$ obtained in this study in comparison with literature values. 
Figure 5. Normalized SA dependence on particle size effect obtained in our study as well as literature experimental and theoretical studies. The dashed black line indicates the trend for the theoretically determined discrete values represented by the black squares.

Figure 6. Correlation between SA and fraction of surface terrace atom \% estimated from CO-TPD experiments re-plotted from Perez-Alonso et al. [34] (pink cross). The SA values normalized to SA values of poly-Pt electrodes to depict correlation between SA obtained in this work (blue circles) and the fraction of surface terrace atoms.

Figure 7. MA at $0.9 \mathrm{~V}$ obtained in this work as well as literature experimental and theoretical studies. The absolute values of MA for the theoretical model (Tritsaris et al. [42]) were estimated using the SA of poly-Pt in this work. 


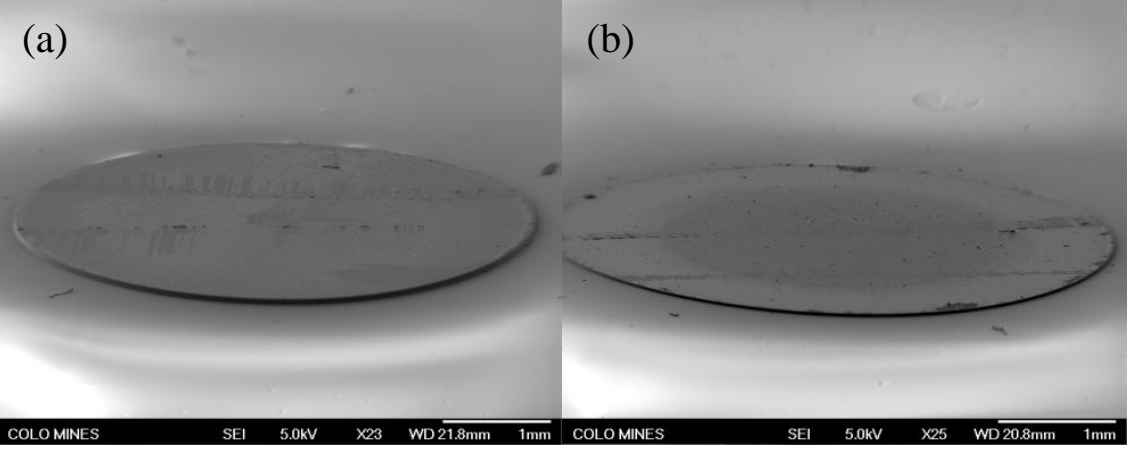

Figure 1 


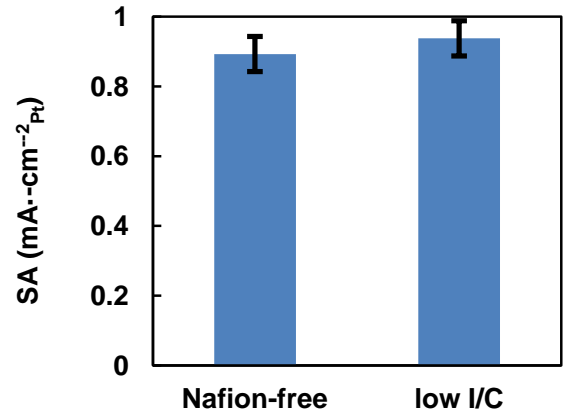

Figure 2 


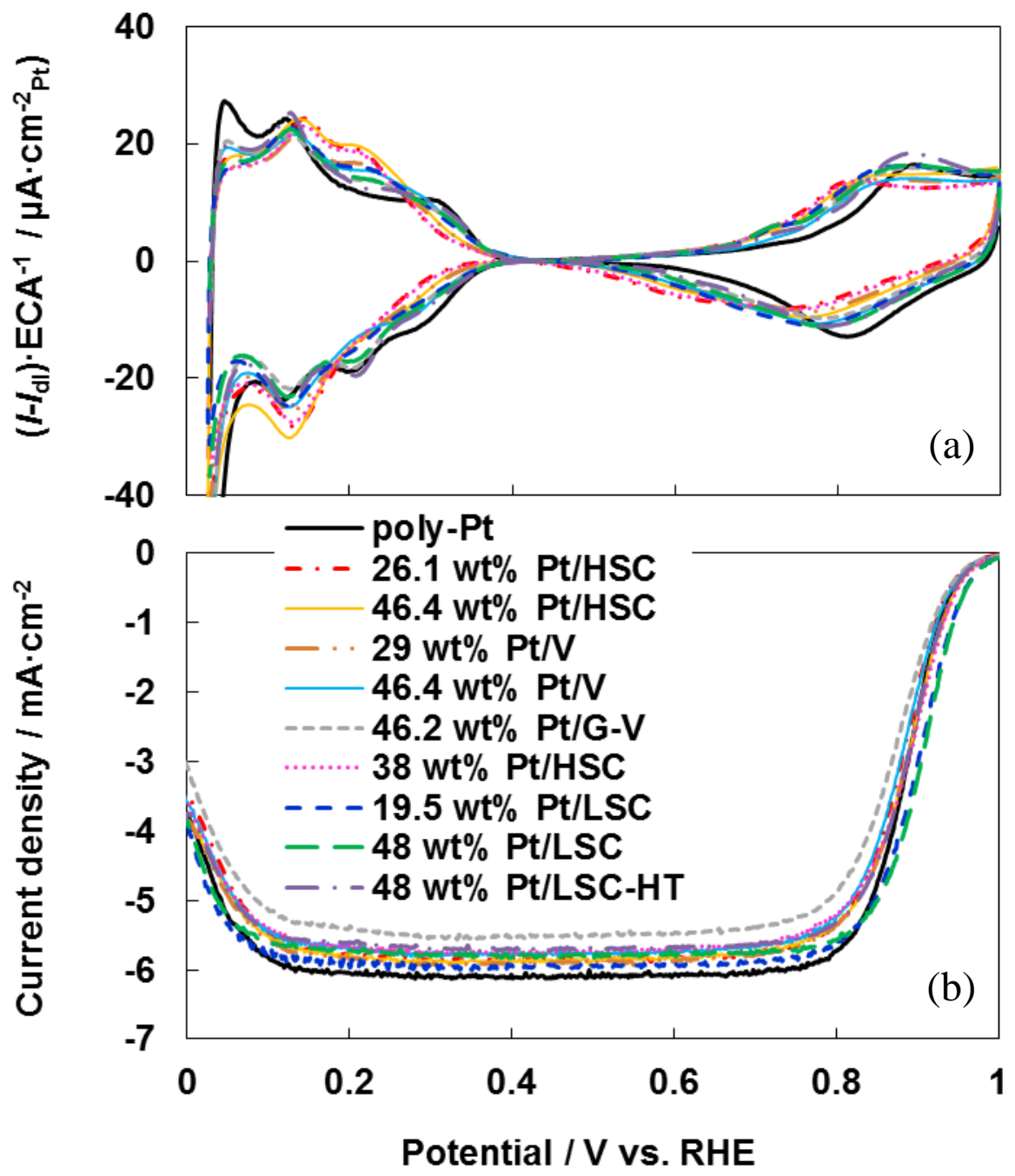

Figure 3 


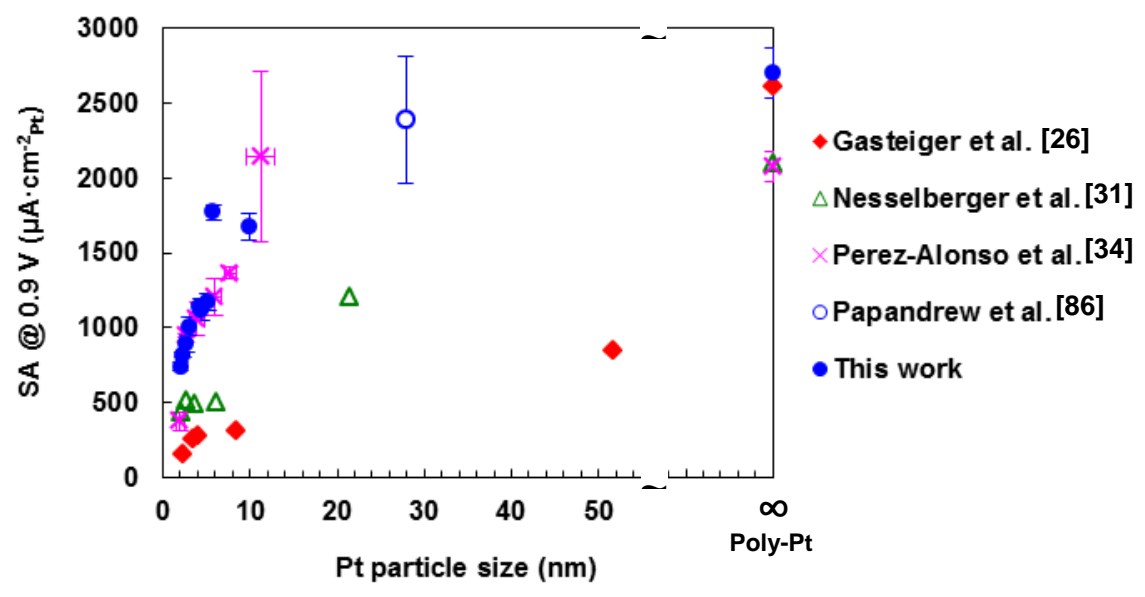

Figure 4 


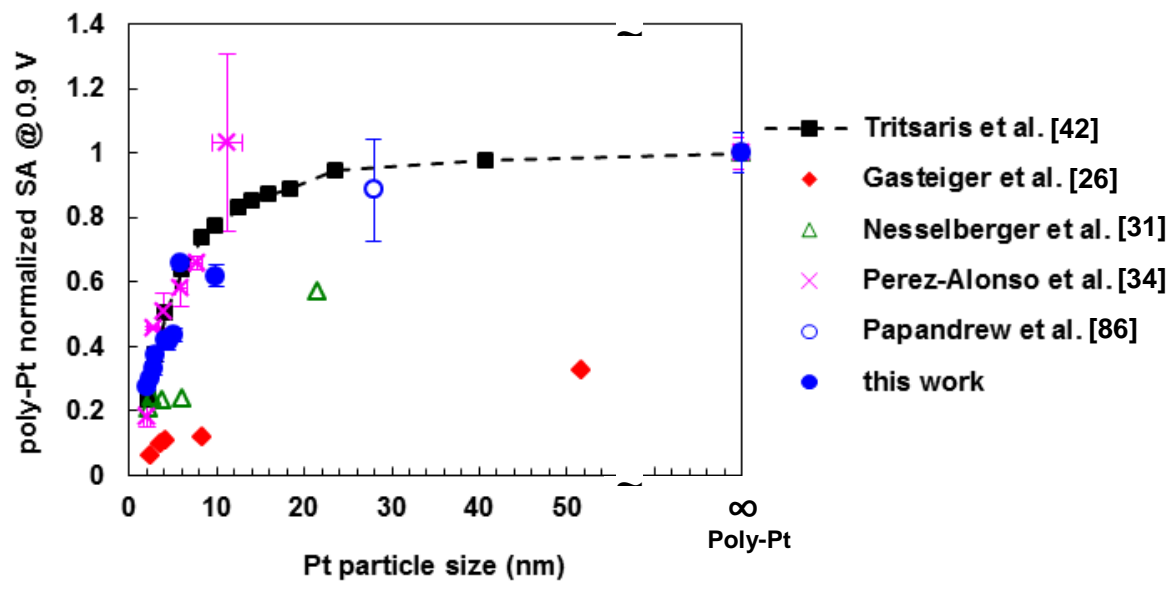

Figure 5 


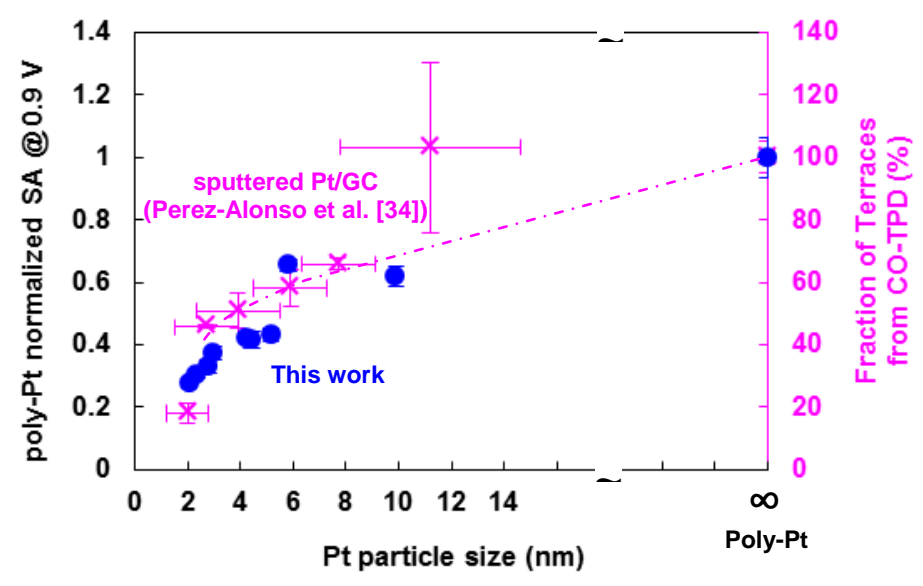

Figure 6 


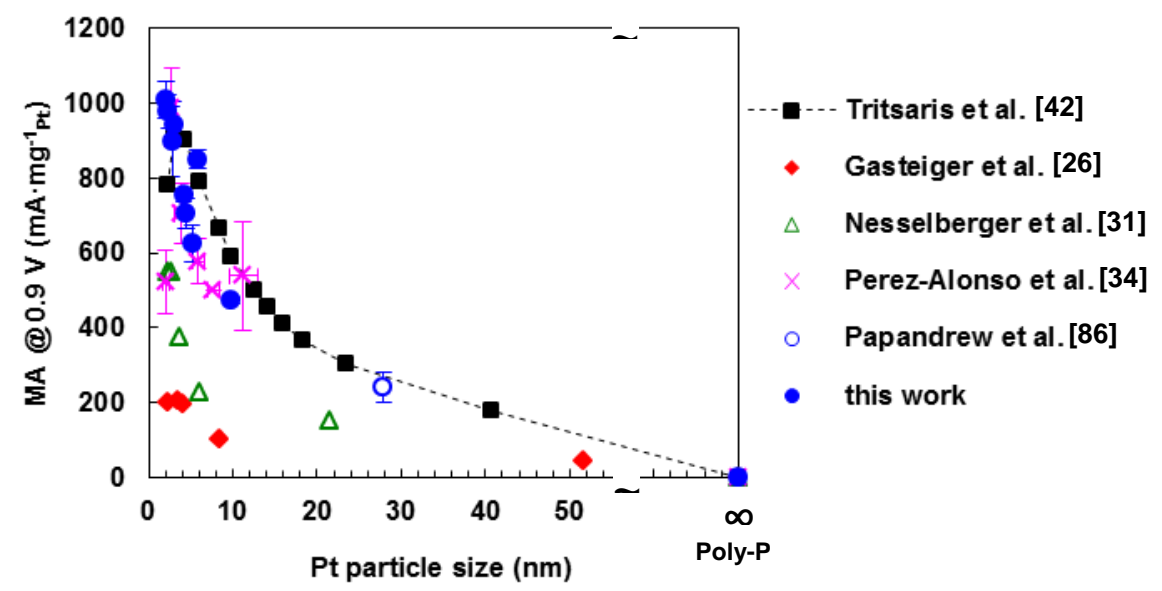

Figure 7 